\title{
Mudança estrutural no mercado brasileiro de automóveis
}

\author{
Ísis Gomes Semenzato de Souza* \\ Danilo R. D. Aguiar ${ }^{* * *}$
}

\begin{abstract}
Resumo
Este trabalho analisa as mudanças estruturais que ocorrem no mercado brasileiro de automóveis desde a década de 1990. Identificou-se a redução contínua da concentração de mercado, com a concorrência da entrada de novas firmas. Apesar disso, o mercado brasileiro é ainda muito concentrado. Em termos de comércio internacional, detectouse um novo padrão, com a transformação do país de exportador líquido para importador líquido de veículos. Os tipos de carros vendidos no Brasil também mudaram, uma vez que a participação de carros populares está diminuindo. Isso é consequência do aumento da renda dos consumidores e da maior oferta de crédito. Outro aspecto identificado no estudo foi a redução na parcela de mercado dos estados tradicionais (São Paulo e Minas Gerais).

Palauras-chave: Mercado brasileiro de automóveis. Concentração de mercado. Concorrência.
\end{abstract}

" Economista. Analista financeira da Whirlpool Latin America. E-mail: isisesemenzato@gmail.com

* Professor titular do Departamento de Economia do Centro de Ciências em Gestão e Tecnologia, Universidade Federal de São Carlos, campus Sorocaba, Rd. SP 264, Km 110, CEP 18.052-780, Sorocaba, SP. E-mail: danilo@ufscar.br

http://dx.doi.org/10.5335/rtee.v21i445.6188

Submissão: 23/07/2015. Aceite: 26/02/2016. 


\section{Introdução}

A indústria automobilística brasileira desenvolveu-se em um ambiente caracterizado pela forte intervenção governamental e por mudanças nas condições de mercado, fatores que, conjuntamente, afetam a estrutura de mercado e o grau de concorrência do setor. Em termos de políticas públicas, até a década de 1990, o setor operava em um regime de economia fechada, com quatro firmas dominando praticamente todo o mercado. Durante aquela década, teve início a abertura de mercado, quando o governo chegou a reduzir as tarifas de importação de $80 \%$, em 1990, para 35\%, em 1994. Em 1995, o governo federal instituiu o Regime Automotivo Brasileiro, ${ }^{3}$ que estabelecia medidas de incentivo à modernização industrial e ao investimento no setor automotivo. Esse programa foi complementado pelo regime especial, implementado por meio da MP no 1.532, de 1997, com o objetivo de direcionar os investimentos especificamente para as regiões Norte, Nordeste e Centro-Oeste, tanto para montadoras como para empresas de autopeças, por meio de benefícios fiscais para empresas que se localizassem nessas regiões.

Conforme mostra Pinho (1999), o regime automotivo atraiu mais firmas para o mercado, elevou expressivamente a participação dos automóveis importados e promoveu o início de um processo de descentralização regional da produção, que antes se concentrava em dois estados (São Paulo e Minas Gerais). Ainda, nesse regime, foi de grande importância o papel do Banco Nacional de Desenvolvimento Econômico e Social (BNDES), apoiando financeiramente multinacionais do setor e impulsionando o crescimento de unidades produtoras no Brasil (BARROS; PEDRO, 2010).

Mais recentemente, houve ainda duas medidas políticas de grande importância: a isenção do Imposto sobre Produtos Industrializados (IPI) para a comercialização de automóveis, feita para contrabalançar os efeitos da crise financeira internacional de $2008,{ }^{4}$ que perdurou até 2014 , e o aumento da tributação sobre carros importados, no final de 2011, visando proteger a indústria doméstica.

Paralelamente a essas políticas, também houve mudanças no mercado propriamente dito. A citada crise financeira internacional, que teve seu ápice em 2008, retraiu os mercados consumidores dos países europeus e dos Estados Unidos, aumentando a atratividade do mercado brasileiro. Somando-se a isso, o crescimento da renda (principalmente até 2008), a apreciação do real e a maior oferta de crédito (com taxas de juros mais acessíveis) incrementaram a possibilidade de compra de automóveis por parte dos consumidores brasileiros. 
Diante dessas mudanças, tanto oriundas de políticas econômicas como de variáveis de mercado, há indícios de fortes alterações na estrutura de mercado do setor automobilístico brasileiro nesse início de século XXI. Em comparação com o final do século passado, nota-se a existência de um número muito maior de marcas e modelos de automóveis. Essa e outras tendências, que são apontadas pela mídia ou por especialistas da área, precisam ser mais bem identificadas e mensuradas, para que se saiba, com precisão, o que está ocorrendo no setor automobilístico. Esse conhecimento possibilitaria ao governo ajustar as políticas em curso e delinear outras novas, e aos empresários do setor planejar seus investimentos futuros.

Nesse contexto, o objetivo do presente trabalho é justamente identificar e quantificar as mudanças estruturais pelas quais tem passado a indústria automobilística brasileira desde 1995. Mais especificamente, pretende-se: a) avaliar as mudanças na concentração do mercado automobilístico brasileiro entre as diversas marcas comerciais; b) mensurar as perdas de mercados das marcas tradicionais para as novas marcas ingressantes no mercado brasileiro; c) identificar as mudanças na participação dos diversos segmentos da indústria nas vendas do setor; d) medir as mudanças espaciais na produção brasileira de automóveis.

\section{Metodologia}

\subsection{Referencial teórico}

A preocupação com a estrutura de mercado e com seu impacto no poder de mercado das firmas ganhou destaque, inicialmente, com o modelo estrutura-conduta-desempenho (ECD), desenvolvido a partir do artigo seminal de Mason (1939). Esse modelo procura explicar o relacionamento entre a estrutura do mercado, as condutas empresariais e o desempenho econômico.

De acordo com o modelo ECD, a estrutura de mercado seria caracterizada por três condicionantes: a) número de firmas e sua distribuição do mercado; b) grau de diferenciação do produto; c) condições de entrada de concorrentes no mercado. A partir desses fatores, as firmas teriam maior ou menor grau de poder de mercado, que causariam maior ou menor dano ao bem-estar social. Assim, por exemplo, em um mercado com poucas firmas, produtos diferenciados e barreiras à entrada de concorrentes, seria possível às firmas a adoção de estratégias para manter lucros supranormais, o que reduziria o bem-estar social.

Dessa forma, a desconcentração do mercado, a redução de barreiras à entrada e o ingresso de mais firmas no mercado trariam benefícios à sociedade, na forma de 
maior oferta de produtos, preços mais acessíveis, melhor qualidade, maior variedade, etc. Logo, seria importante identificar as transformações na estrutura do mercado para, a partir disso, avaliar o grau de bem-estar que a sociedade pode atingir.

\subsection{Método empírico}

\subsubsection{Delimitação da indústria e fonte de dados}

O mercado relevante considerado nesta pesquisa é o mercado consumidor nacional de automóveis e comerciais leves, ou seja, também são levados em conta no estudo, veículos como picape, não sendo considerados ônibus ou caminhões. $\mathrm{Na}$ análise do mercado consumidor, foram incluídos os veículos produzidos no exterior e comercializados internamente e excluídos os veículos produzidos no país que são exportados.

Para caracterizar a estrutura de mercado e a participação das importações no setor, foram utilizados dados da Associação Nacional de Fabricantes de Veículos Automotores (Anfavea) (2013), somente das vendas internas de automóveis e comerciais leves por modelo e por empresa. Esses dados, referentes a vendas internas, incluem empresas consideradas nacionais (com montadoras no Brasil) e estrangeiras (sem montadoras em território nacional). Além desses, foram utilizados dados de licenciamentos de automóveis e comerciais leves importados e para exportados, para verificar o fluxo comercial do mercado. Esse balanço comercial considera as transações de empresas nacionais e estrangeiras.

Para observar as diferentes categorias de automóveis e comerciais leves comercializados no país, foram considerados apenas os veículos emplacados oriundos de empresas nacionais, devido à inexistência de informações precisas sobre as características de todos os modelos estrangeiros que permitissem classificá-los por categoria.

Com a finalidade de observar mais detalhadamente o mercado de automóveis importados, foram utilizados dados de vendas de veículos automotores no atacado, por marca, da Associação Brasileira de Empresas Importadoras de Veículos Automotores (Abeiva), que consideram apenas empresas que não tinham montadoras em território nacional durante o período estudado.

Por fim, visando observar a distribuição geográfica da oferta no mercado brasileiro, foram utilizados dados de produção nacional de automóveis e comerciais leves por empresa e por estado da federação. 


\subsubsection{Indicadores da estrutura de mercado}

Para identificar as mudanças na estrutura de mercado da indústria automobilística, diversos indicadores estruturais são estimados e avaliados. ${ }^{5} \mathrm{O}$ indicador base, que tanto representa, em si, a concentração de mercado quanto é substrato para o cálculo de outros indicadores, é a participação de mercado de cada firma. A parcela de mercado da firma $i\left(s_{i}\right)$ é dada por:

$$
s_{i}=\frac{q_{i}}{\sum_{j=1}^{N} q_{j}}
$$

Em que $s_{i}$ representa a parcela de mercado da firma $i ; q_{i}$, a quantidade vendida pela firma $i ; q_{j}$, a quantidade vendida pela firma $j$; e $N$, o número de firmas no mercado.

A partir da parcela de mercado de cada firma, são calculadas as taxas de concentração por segmento produtivo das $k$ maiores firmas da seguinte forma:

$$
C R k=\sum_{i=1}^{k} s_{i}
$$

Em que $C R k$ representa a taxa de concentração das $k$-ésimas maiores firmas; $s_{i}$, a parcela de mercado da firma $i$.

Outro índice para concentração de mercado utilizado neste trabalho é o índice de Herfindahl-Hirschman $(H)$, calculado da seguinte forma:

$$
\mathrm{H}=\sum_{\mathrm{i}=1}^{\mathrm{N}} \mathrm{s}_{\mathrm{i}}^{2}
$$

Em que $s_{i}$ é a parcela decimal (ou percentual) de mercado de cada uma das firmas do mercado estudado. $\mathrm{O}$ índice $H$ varia de 0 a 1 , sendo que quanto mais se aproximar de 1 (que ocorreria no caso de um monopólio), maior seria a concentração, e quanto mais próximo de zero, menos concentrado seria o mercado. Além disso, quanto menos firmas houver no mercado e quanto maior a desigualdade entre elas, maior será o valor do índice $H$. Outra característica desse índice é que se as firmas forem todas do mesmo tamanho, o valor do $H$ será igual a um dividido 
pelo número de firmas, o que permite calcular o número de firmas iguais $\left(N^{*}\right)$ que gerariam determinado valor de $H\left(H^{*}\right): N^{*}=1 / H^{*}$.

\section{Resultados}

\subsection{Concentração de mercado}

As estimativas apresentadas no Quadro 1, e ilustradas na Figura 1, evidenciam um contínuo decréscimo na concentração do mercado brasileiro de automóveis, que, a despeito dessa tendência, permanece altamente concentrado. Nota-se que as quatro maiores firmas detinham participação de quase $100 \%$ do mercado no início da década de 1990, participação que só se tornou inferior a $90 \%$ a partir de 1998 , abaixo de $80 \%$ a partir de 2008 , situando-se em torno de $70 \%$ nos últimos dois anos de análise (2011 e 2012).

Em termos médios, o CR4 da década de 1990 foi de $94,23 \%$, o da década seguinte foi de $81,96 \%$, reduzindo-se ainda mais nos três primeiros anos da presente década (para 71,63\%). A despeito dessa redução da concentração, deve-se notar, como se analisará em mais detalhes no próximo item, que as quatro maiores firmas foram as mesmas durante todo o período: Fiat, General Motors, Volkswagen e Ford.

Quadro 1 - Taxas de concentração das quatro maiores firmas (CR4) no mercado brasileiro de automóveis e comerciais leves, 1990-2012

\begin{tabular}{|c|c|c|c|}
\hline Ano & CR4 & Ano & CR4 \\
\hline 1990 & $98,78 \%$ & 2002 & $84,14 \%$ \\
1991 & $96,48 \%$ & 2003 & $86,42 \%$ \\
1992 & $97,95 \%$ & 2004 & $79,66 \%$ \\
1993 & $96,54 \%$ & 2005 & $81,65 \%$ \\
1994 & $94,07 \%$ & 2006 & $81,57 \%$ \\
1995 & $92,54 \%$ & 2007 & $80,88 \%$ \\
1996 & $94,93 \%$ & 2008 & $76,88 \%$ \\
1997 & $93,87 \%$ & 2009 & $77,20 \%$ \\
1998 & $89,52 \%$ & 2010 & $73,75 \%$ \\
1999 & $87,66 \%$ & 2011 & $70,19 \%$ \\
2000 & $85,77 \%$ & 2012 & $70,94 \%$ \\
2001 & $85,47 \%$ & - & - \\
\hline
\end{tabular}

Fonte: elaboração dos autores com base em dados da Anfavea. 
Figura 1 - Evolução da taxa de concentração das quatro maiores firmas $(C R 4)$ da indústria automobilística brasileira, 1990-2012

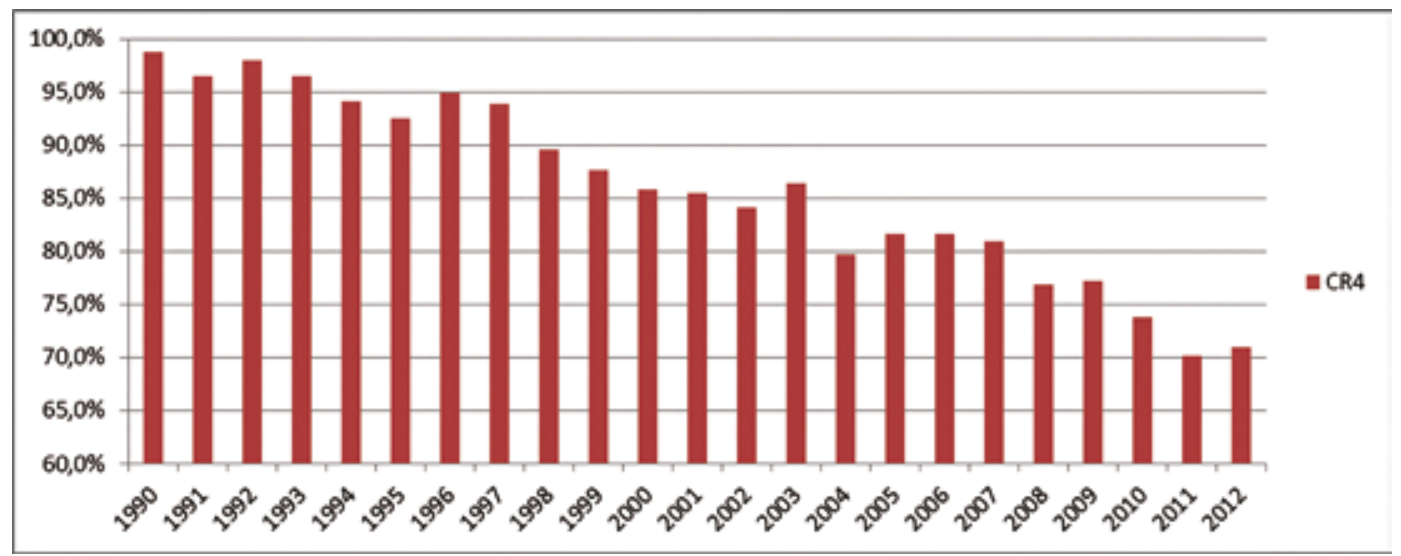

Fonte: elaboração dos autores com base em dados da Anfavea.

A mesma tendência de desconcentração transparece no comportamento do índice de Herfindahl-Hirschman, conforme as estimativas apresentadas no Quadro 2 e ilustradas na Figura 2. Esse índice reduziu-se de algo próximo a 0,28, o que indicava tanto elevada concentração quanto desigualdade entre as parcelas de mercado das firmas, para aproximadamente 0,16. Para ilustrar a desigualdade entre as firmas, tomando-se o ano de 2005 como exemplo, verifica-se que, embora houvesse 23 empresas vendendo automóveis no mercado doméstico brasileiro naquele ano, o índice $H$ (estimado em 0,1826 ) era compatível com um mercado em que houvesse entre cinco e seis firmas de mesmo porte, o que evidencia que, além de elevada concentração, a distribuição do mercado era desuniforme mesmo no grupo das quatro maiores firmas. Nos anos subsequentes, o índice $H$ foi diminuindo até atingir pouco mais de 0,15 , em 2012, o que equivaleria, naquele ano, a um mercado composto por seis a sete firmas de mesmo porte. 
Quadro 2 - Índices Herfindahl-Hirschman $(H)$ no mercado brasileiro de automóveis e comerciais leves, 1990-2012

\begin{tabular}{|c|c|c|c|}
\hline Ano & $H$ & Ano & CR4 \\
\hline 1990 & 0,2756 & 2002 & 0,2010 \\
1991 & 0,2533 & 2003 & 0,2078 \\
1992 & 0,2721 & 2004 & 0,1759 \\
1993 & 0,2567 & 2005 & 0,1826 \\
1994 & 0,2497 & 2006 & 0,1847 \\
1995 & 0,2441 & 2007 & 0,1838 \\
1996 & 0,2573 & 2008 & 0,1698 \\
1997 & 0,2371 & 2009 & 0,1702 \\
1998 & 0,2171 & 2010 & 0,1578 \\
1999 & 0,2196 & 2011 & 0,1500 \\
2000 & 0,2105 & 2012 & 0,1517 \\
2001 & 0,2145 & - & - \\
\hline
\end{tabular}

Fonte: elaboração dos autores com base em dados da Anfavea.

Figura 2 - Evolução do índice de Herfindhal-Hirschman $(H)$ para a indústria automobilística brasileira, 1990-2012

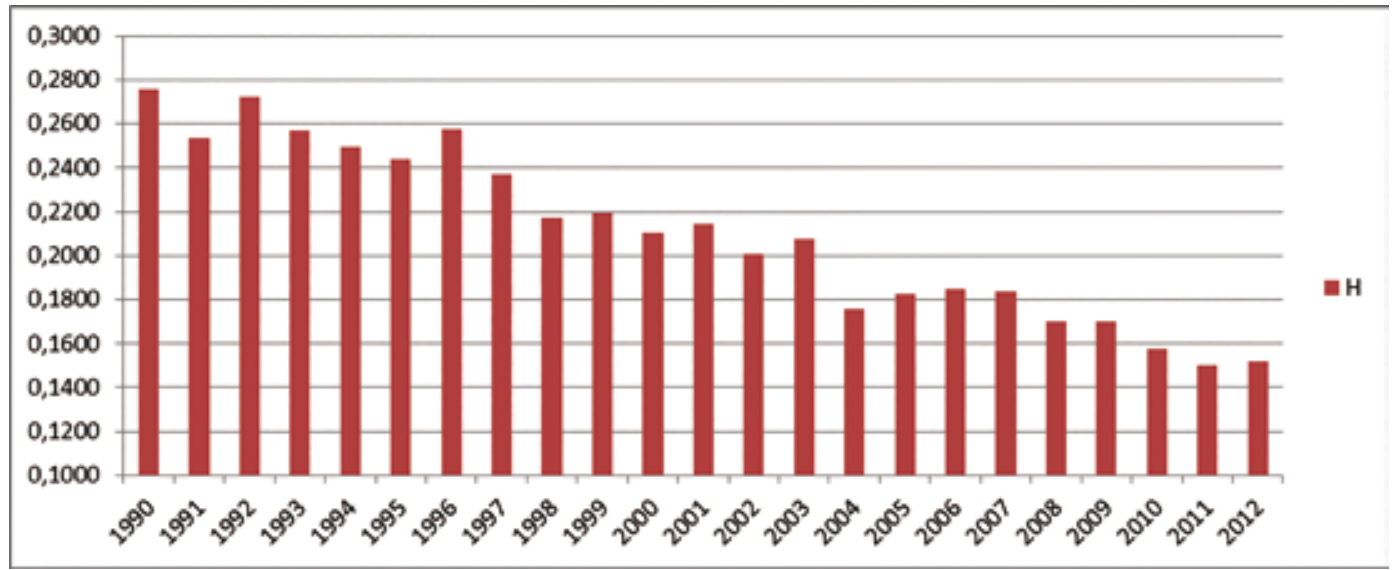

Fonte: elaboração dos autores com base em dados da Anfavea.

A redução do índice $\mathrm{H}$ decorre tanto da redução da concentração (já evidenciada pelo CR4) quanto pelo ingresso de novos ofertantes no mercado brasileiro. A título de comparação, em 2010 foram comercializados, no Brasil, automóveis produzidos por 43 firmas diferentes (em sua grande maioria, firmas sem montadoras em território nacional), sendo que em 2005 foram comercializados automóveis oriundos de apenas 23 firmas. 
Com base nos indicadores estimados, é possível chegar a duas conclusões. Primeira, que o mercado automobilístico brasileiro pode ser considerado um oligopólio fortemente concentrado. Segunda, que tem havido uma tendência de desconcentração do mercado, mais acentuada nos anos de 2004, 2008 e 2010.

Em 2004, a desconcentração deveu-se, principalmente, à maturação de novos investimentos realizados no final da década de 1990, ao bom desempenho macroeconômico do país e ao aumento das importações de automóveis (assunto a ser explorado na seção 3.3). Em 2008, os destaques foram as políticas adotadas para compensar os efeitos da crise financeira mundial (entre fim de 2008 e início de 2009), como a isenção total do IPI para compra de automóveis, máquinas e equipamentos e a expansão do crédito à aquisição de automóveis. Já em 2010, houve continuidade do regime especial, que era vigente até aquele ano.

A título de comparação, em 2012, a parcela das quatro maiores firmas produtoras de automóveis situava-se em torno de 55\%, tanto nos Estados Unidos quanto no Canadá, sendo que as mesmas firmas estavam no grupo das quatro maiores em ambos os países (Ford, Chrysler, GM e Toyota). ${ }^{6}$ Embora essas estimativas tenham sido feitas com dados de produção, e não de consumo, elas sugerem que ainda há espaço para a concentração do mercado brasileiro continuar diminuindo, sem que haja perdas devido a economias de escala.

\subsection{Parcelas de mercado}

Por meio das parcelas de mercado $\left(s_{i}\right)$ é possível identificar como a redução da concentração do mercado afetou cada uma das firmas. No Quadro 3, são apresentadas as parcelas das onze principais firmas com montadoras em território brasileiro, sendo as demais agrupadas na categoria denominada outros. Nota-se uma disputa entre Fiat, General Motors e Volkswagen, que têm se alternado nas três primeiras posições no ranking de vendas internas ao longo do período, enquanto a Ford se mantém consistentemente na quarta posição.

Em termos de evolução, no Quadro 3, verifica-se que as três maiores empresas tiveram redução de suas parcelas de mercado entre 2000 e 2012. No caso da Ford, a empresa representou cerca de $10 \%$ do mercado, com pequena variação positiva entre o início e o fim do período analisado. Esses números mostram, firma a firma, o padrão que já havia sido identificado por meio da estimação dos índices $C R 4$ e $H$ : as firmas maiores perdendo parcelas de mercado para novas ingressantes. 
Quadro 3 - Parcelas de mercado (em \%) das firmas no mercado brasileiro de automóveis e comerciais leves, 2000 a 2012, e variação percentual das parcelas entre o início e o final

\begin{tabular}{|c|c|c|c|c|c|c|c|c|c|}
\hline \multicolumn{10}{|c|}{ Anos 2000 a 2006} \\
\hline Ano & 2000 & 2001 & \multicolumn{2}{|c|}{2002} & \multicolumn{2}{|c|}{2003} & 2004 & 2005 & 2006 \\
\hline Fiat & 25,76 & 27,49 & \multicolumn{2}{|c|}{25,47} & \multicolumn{2}{|c|}{26,37} & 22,88 & 24,98 & 25,42 \\
\hline Volkswagen & 27,92 & 27,56 & \multicolumn{2}{|c|}{25,43} & \multicolumn{2}{|c|}{22,55} & 21,77 & 21,97 & 22,54 \\
\hline GM & 23,50 & 23,15 & \multicolumn{2}{|c|}{24,10} & \multicolumn{2}{|c|}{25,81} & 23,91 & 22,56 & 22,38 \\
\hline Ford & 8,58 & 7,26 & \multicolumn{2}{|c|}{9,13} & \multicolumn{2}{|c|}{11,69} & 11,10 & 12,14 & 11,24 \\
\hline Outras & 2,65 & 1,44 & \multicolumn{2}{|c|}{1,58} & \multicolumn{2}{|c|}{3,56} & 3,57 & 0,74 & 0,86 \\
\hline Renault & 4,03 & 4,66 & \multicolumn{2}{|c|}{4,32} & \multicolumn{2}{|c|}{4,49} & 3,51 & 2,94 & 2,82 \\
\hline Peugeot-Citroën & 2,18 & 3,21 & \multicolumn{2}{|c|}{4,59} & \multicolumn{2}{|c|}{4,36} & 4,18 & 4,96 & 5,24 \\
\hline Honda & 1,45 & 1,45 & \multicolumn{2}{|c|}{1,49} & \multicolumn{2}{|c|}{2,49} & 3,33 & 3,52 & 3,68 \\
\hline Toyota-Lexus & 1,82 & 1,58 & \multicolumn{2}{|c|}{1,83} & \multicolumn{2}{|c|}{3,29} & 3,29 & 3,76 & 3,81 \\
\hline Nissan & 0,02 & 0,10 & \multicolumn{2}{|c|}{0,29} & \multicolumn{2}{|c|}{0,58} & 0,52 & 0,50 & 0,31 \\
\hline Mitsubishi & 0,89 & 0,96 & \multicolumn{2}{|c|}{0,98} & \multicolumn{2}{|c|}{1,20} & 1,37 & 1,41 & 1,28 \\
\hline Mercedes Benz & 1,19 & 1,13 & \multicolumn{2}{|c|}{0,79} & \multicolumn{2}{|c|}{0,72} & 0,57 & 0,52 & 0,44 \\
\hline \multicolumn{10}{|c|}{ Anos 2007 a 2012 e variação } \\
\hline Ano & 2007 & 2008 & 2009 & \multicolumn{2}{|c|}{2010} & 2011 & 2012 & Variação ir & o-final \\
\hline Fiat & 25,95 & 24,63 & 24,49 & & & 22,02 & 23,07 & & $48 \%$ \\
\hline Volkswagen & 23,08 & 21,96 & 22,81 & & & 20,55 & 21,28 & & $79 \%$ \\
\hline GM & 21,30 & 20,55 & 19,79 & & & 18,46 & 17,68 & & $4 \%$ \\
\hline Ford & 10,55 & 9,74 & 10,10 & & & 9,17 & 8,91 & & $76 \%$ \\
\hline Outras & 1,59 & 3,25 & 4,22 & & 60 & 9,36 & 6,68 & & $90 \%$ \\
\hline Renault & 3,14 & 4,31 & 3,91 & & 82 & 5,67 & 6,65 & & $85 \%$ \\
\hline Peugeot-Citroën & 5,48 & 5,65 & 5,02 & & 24 & 5,13 & 4,04 & & $04 \%$ \\
\hline Honda & 3,66 & 4,40 & 4,18 & & 80 & 2,71 & 3,71 & & $53 \%$ \\
\hline Toyota-Lexus & 3,08 & 3,03 & 3,11 & & 99 & 2,90 & 3,13 & & $49 \%$ \\
\hline Nissan & 0,51 & 0,65 & 0,77 & & 08 & 1,96 & 2,88 & 151 & $46 \%$ \\
\hline Mitsubishi & 1,25 & 1,54 & 1,25 & & 34 & 1,62 & 1,67 & & $13 \%$ \\
\hline Mercedes Benz & 0,40 & 0,29 & 0,34 & & 39 & 0,45 & 0,30 & & $43 \%$ \\
\hline
\end{tabular}

Fonte: elaboração dos autores com base em dados da Anfavea. 
É importante observar também o crescimento da participação da categoria outros, que foi contínua desde 2005 até 2011, havendo interrupção dessa tendência em 2012. Outro aspecto a ser salientado é que todas as sete outras firmas, além das quatro maiores, instalaram-se para produção de automóveis no Brasil entre 1998 e 2002. Segundo Costa e Henkin (2012), são elas: Honda, em 1997, Mitsubishi e Toyota, em 1998, Mercedes-Benz e Renault, em 1999, Peugeot-Citroën, em 2001, e Nissan, em 2002. Essas informações evidenciam a entrada de novas firmas no mercado, tanto por meio de novas instalações no território nacional quanto por importações. Tais fatos serão mais bem explorados na próxima seção, ao se analisar as importações.

\subsection{Intercâmbio com o exterior}

São opostas as direções das importações e exportações do mercado automotivo brasileiro (Figura 3). Com algumas flutuações, as importações diminuíram até 2004, crescendo desde então, enquanto que as exportações cresceram até 2005, passando depois a diminuir. Enquanto o pico das exportações se deu em 2005, o das importações ocorreu em 2011. A queda das exportações é decorrência natural do crescimento da demanda doméstica brasileira e da apreciação cambial, fatos que também influenciaram o aumento das importações de veículos até 2011, sendo que a redução das importações em 2012 foi resultado direto da mudança da política comercial brasileira.

Ao final de 2011, o governo federal aumentou a alíquota do IPI em trinta pontos percentuais para automóveis importados de países diferentes dos pertencentes ao Mercosul, acréscimo que entrou em vigor em janeiro de 2012. Tal medida foi tomada justamente com a finalidade de interromper a tendência crescente das importações. 
Figura 3 - Fluxo comercial de automóveis e comerciais leves

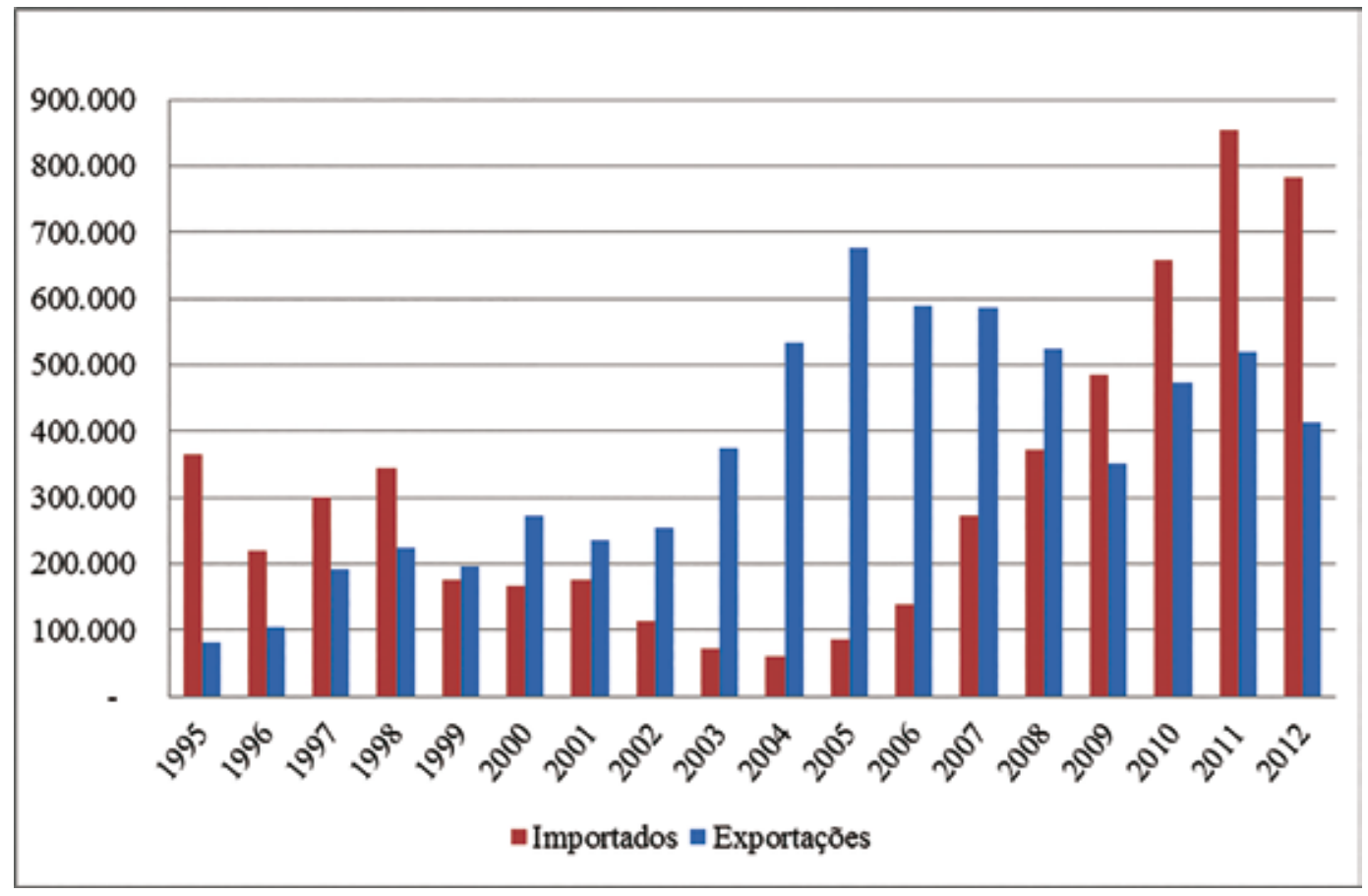

Fonte: elaboração dos autores com base em dados da Anfavea.

Para explorar mais detalhadamente o fluxo de importações, deve-se atentar à importação de veículos de empresas que não mantêm montadoras no Brasil. Considerando as duas últimas décadas, pode-se identificar dois grandes destaques nas vendas internas de veículos dessas empresas: uma interrupção em 2001 e uma nova interrupção em 2012 (Quadro 4). 
Quadro 4 - Vendas internas de veículos de empresas estrangeiras, 1991-2012

\begin{tabular}{|c|c|c|c|}
\hline Ano & Total & $\begin{array}{c}\text { Participação no total de } \\
\text { importados }\end{array}$ & Variação anual \\
\hline 1991 & 15.691 & $79,1 \%$ & $-31,8 \%$ \\
1992 & 10.704 & $21,1 \%$ & $231,8 \%$ \\
1993 & 35.519 & $51,4 \%$ & $119,5 \%$ \\
1994 & 77.962 & $42,3 \%$ & $53,3 \%$ \\
1995 & 119.543 & $32,8 \%$ & $-51,0 \%$ \\
1996 & 58.533 & $26,7 \%$ & $-2,6 \%$ \\
1997 & 57.027 & $19,0 \%$ & $9,7 \%$ \\
1998 & 62.537 & $18,2 \%$ & $-18,2 \%$ \\
1999 & 51.157 & $29,2 \%$ & $24,0 \%$ \\
2000 & 63.455 & $38,1 \%$ & $-73,1 \%$ \\
2001 & 17.086 & $9,7 \%$ & $-49,7 \%$ \\
2002 & 8.593 & $7,6 \%$ & $-56,8 \%$ \\
2003 & 3.716 & $5,2 \%$ & $2,2 \%$ \\
2004 & 3.797 & $6,4 \%$ & $43,1 \%$ \\
2005 & 5.434 & $6,4 \%$ & $8,5 \%$ \\
2006 & 5.894 & $4,2 \%$ & $111,9 \%$ \\
2007 & 12.491 & $4,6 \%$ & $154,1 \%$ \\
2008 & 31.742 & $8,6 \%$ & $49,0 \%$ \\
2009 & 47.294 & $9,7 \%$ & $-62,6 \%$ \\
2010 & 119.133 & $18,1 \%$ & $-31,8 \%$ \\
2011 & 249.689 & $29,2 \%$ & \\
2012 & 93.342 & & \\
\hline
\end{tabular}

Fonte: elaboração dos autores com base em dados da Abeiva.

Em 2012, havia 27 indústrias automobilísticas estrangeiras vendendo no mercado brasileiro. Contrastado com as quatro empresas que atuavam no mercado em 2004 e com as dezenove que atuavam em 2000, esse número ressalta a volatilidade da entrada e da saída de firmas estrangeiras no mercado de automóveis do Brasil. 


\subsection{Participação por categoria de automóvel}

Utilizando os critérios da Federação Nacional da Distribuição de Veículos Automotores (Fenabrave), os automóveis podem ser divididos em quinze categorias (Quadro 5), o que permite identificar diferentes tendências, algumas delas perdurando ao longo de todo o período analisado. As variações mais acentuadas são dos automóveis de entrada, ${ }^{7}$ cuja participação tem decrescido mais de $1 \%$ ao ano, e dos Hatchs pequenos, categoria superior e mais próxima aos automóveis de entrada, cuja participação tem aumentado continuamente. A categoria sedãs pequenos, apesar de inconstante, também apresenta aumentos expressivos de participação, destacando-se, ainda, o aumento da participação de SUVs, Sedans médios e Pick-ups.

Quadro 5 - Parcelas de automóveis emplacados por categoria (em \%), 2005-2012

\begin{tabular}{|l|r|r|r|r|r|r|r|r|}
\hline \multicolumn{1}{|c|}{ Categoria } & \multicolumn{1}{|c|}{2005} & \multicolumn{1}{c|}{2006} & \multicolumn{1}{c|}{2007} & \multicolumn{1}{c|}{2008} & \multicolumn{1}{c|}{2009} & \multicolumn{1}{c|}{2010} & \multicolumn{1}{c|}{2011} & \multicolumn{1}{c|}{2012} \\
\hline Entrada & 37,89 & 36,38 & 34,49 & 32,85 & 31,50 & 29,16 & 27,72 & 26,60 \\
Furgão & 2,64 & 2,73 & 2,76 & 3,35 & 2,93 & 3,33 & 3,66 & 3,40 \\
Grandcab & 1,98 & 1,33 & 1,12 & 1,03 & 0,87 & 0,69 & 0,62 & 0,47 \\
Hatch médio & 4,01 & 3,74 & 4,58 & 5,64 & 5,44 & 5,92 & 5,64 & 4,31 \\
Hatch pequeno & 13,11 & 12,94 & 12,47 & 11,80 & 11,72 & 14,00 & 14,59 & 17,49 \\
Monocab & 4,78 & 5,11 & 4,19 & 3,94 & 4,32 & 4,14 & 4,11 & 3,39 \\
Outros & 0,05 & 0,06 & 0,03 & 0,03 & 0,03 & 0,03 & 0,03 & 0,02 \\
Pick-up & 8,51 & 8,15 & 8,18 & 8,96 & 9,17 & 10,80 & 11,61 & 10,89 \\
Sedan grande & 0,44 & 0,47 & 0,35 & 0,50 & 0,57 & 0,58 & 0,90 & 0,57 \\
Sedan médio & 4,61 & 6,50 & 6,91 & 7,59 & 6,42 & 5,29 & 5,86 & 7,18 \\
Sedan pequeno & 13,96 & 14,19 & 16,05 & 15,20 & 18,20 & 17,66 & 15,63 & 16,22 \\
Sport & 0,04 & 0,05 & 0,06 & 0,07 & 0,07 & 0,10 & 0,16 & 0,09 \\
SUVs & 4,36 & 4,20 & 4,70 & 5,56 & 5,56 & 6,27 & 7,48 & 7,43 \\
SW grande & 0,54 & 0,53 & 0,70 & 0,37 & 0,15 & 0,13 & 0,35 & 0,41 \\
SW médio & 3,09 & 3,62 & 3,41 & 3,11 & 3,05 & 1,89 & 1,67 & 1,53 \\
\hline
\end{tabular}

Fonte: elaboração dos autores com base em dados da Fenabrave.

Esse padrão, que pode ser visualizado nas Figuras 4 e 5, evidencia a migração dos consumidores da aquisição de automóveis mais básicos (de menor conforto, tamanho e menos itens adicionais) para a aquisição de automóveis menos básicos. Por trás dessa tendência estão o aumento da renda dos consumidores e, principalmente, a maior disponibilidade de crédito com taxa de juros mais acessível e prazos mais longos. Ademais, houve maior entrada de carros importados, que, embora tenham melhor qualidade, tornaram-se acessíveis aos consumidores brasileiros. 
Figura 4 - Parcelas de automóveis emplacados por categoria em 2005

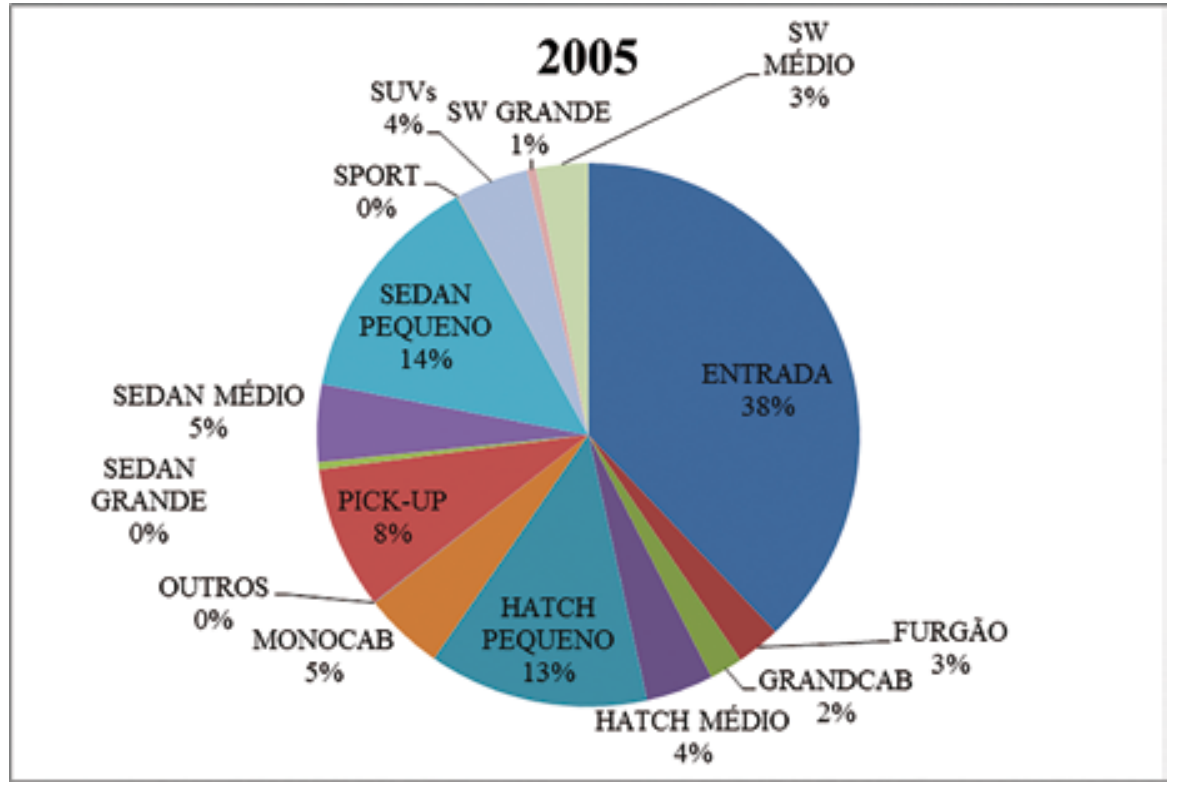

Fonte: elaboração dos autores com base em dados da Fenabrave.

Figura 5 - Parcelas de automóveis emplacados por categoria em 2012

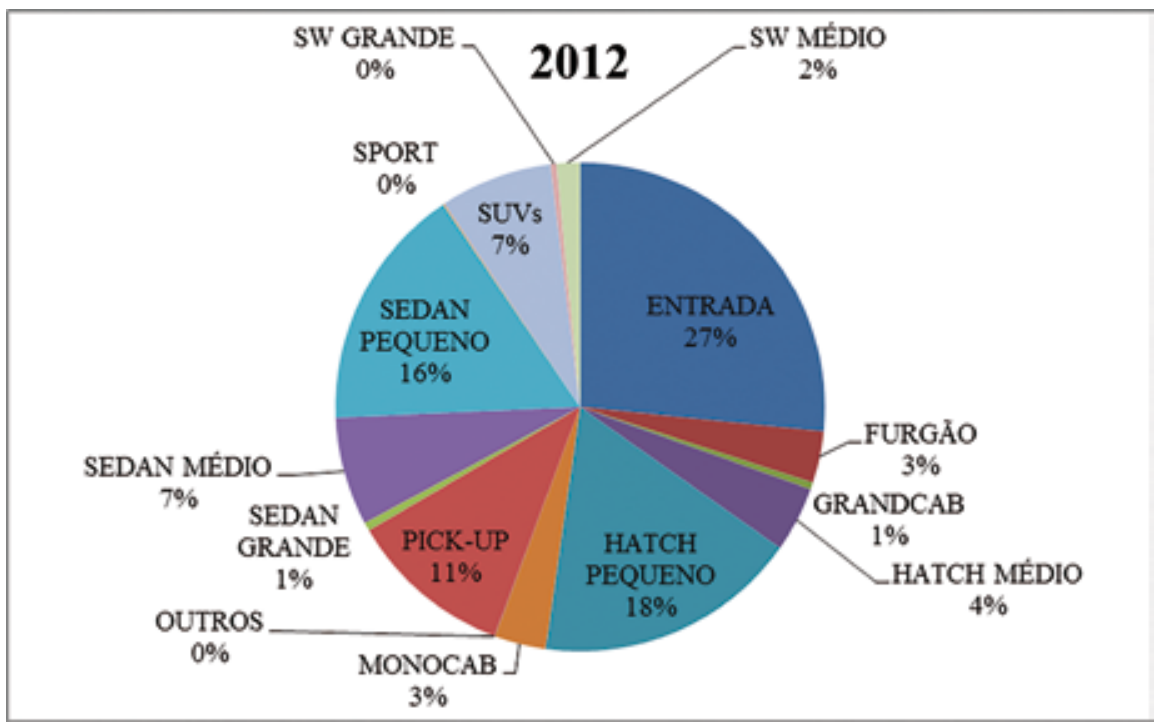

Fonte: elaboração dos autores com base em dados da Fenabrave. 
Além das categorias oriundas da classificação da Fenabrave, um segmento de grande importância no mercado brasileiro é o de carros populares (mil cilindradas), que, por apresentarem vantagens fiscais, foi o elemento mais dinâmico da indústria brasileira até recentemente. Como se verifica na Figura 6, havia tendência de aumento da participação de carros populares no mercado brasileiro na maior parte da década, que descontinua após 2010, ano que se caracterizou pelo aumento substancial da importação de carros (cerca de 150\%), especialmente da China (com preços de carros populares, mas com potência maior do que mil cilindradas).

Figura 6 - Participação de automóveis de mil cilindradas nas vendas internas

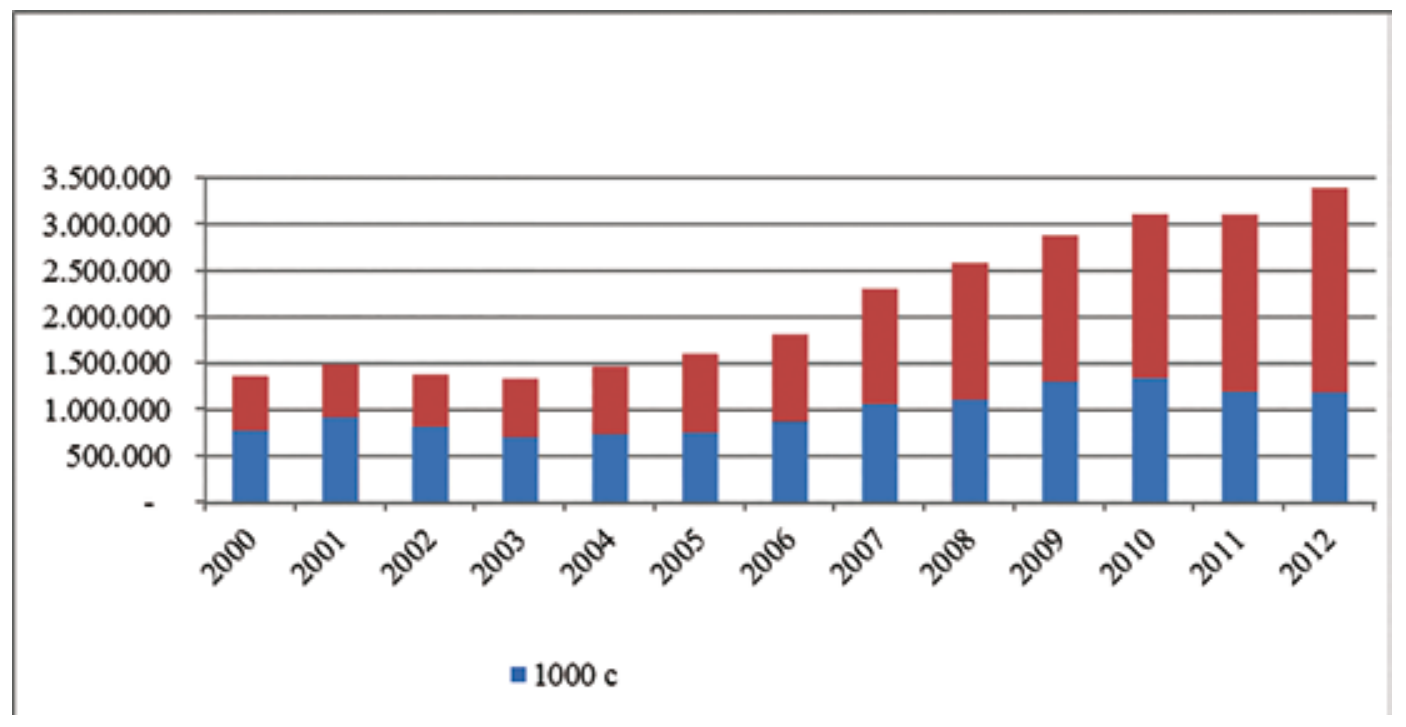

Fonte: elaboração dos autores com base em dados da Anfavea.

Dentre as três maiores firmas sem montadoras em território brasileiro, duas (Cherry e JAC Motors) entraram no mercado nacional recentemente, entre 2009 e 2010, segundo dados da Abeiva (2012). Apesar de a associação não disponibilizar estatísticas de vendas detalhadas por modelos desde a entrada das empresas no mercado, pelo cenário de 2011, pode-se observar que grande parte das vendas dessas novas firmas é de um único modelo.

No caso da JAC Motors, mais da metade de suas vendas (54\%) são do modelo J3, seu mais compacto automóvel, concorrente de carros populares no Brasil. E no caso da Cherry, quase metade das vendas (46\%) são do modelo $\mathrm{QQ}$, também o mais compacto de seus modelos. 


\subsection{Mudança espacial}

Uma alteração importante na estrutura da indústria automobilística diz respeito à distribuição espacial da produção. Conforme ressaltado no início deste artigo, o regime especial implementado em 1997 tinha dentre seus objetivos atrair a produção de automóveis para as regiões novas. Isso está realmente ocorrendo. Nota-se que, entre 1990 e 2012, a participação dos dois principais estados produtores (São Paulo e Minas Gerais) reduziu-se de 100\% para menos de 70\% (Figura 7). Em especial, nota-se a queda da participação de São Paulo, que foi reduzida de $75 \%$ para $40 \%$.

Figura 7 - Participação dos estados brasileiros na produção de automóveis

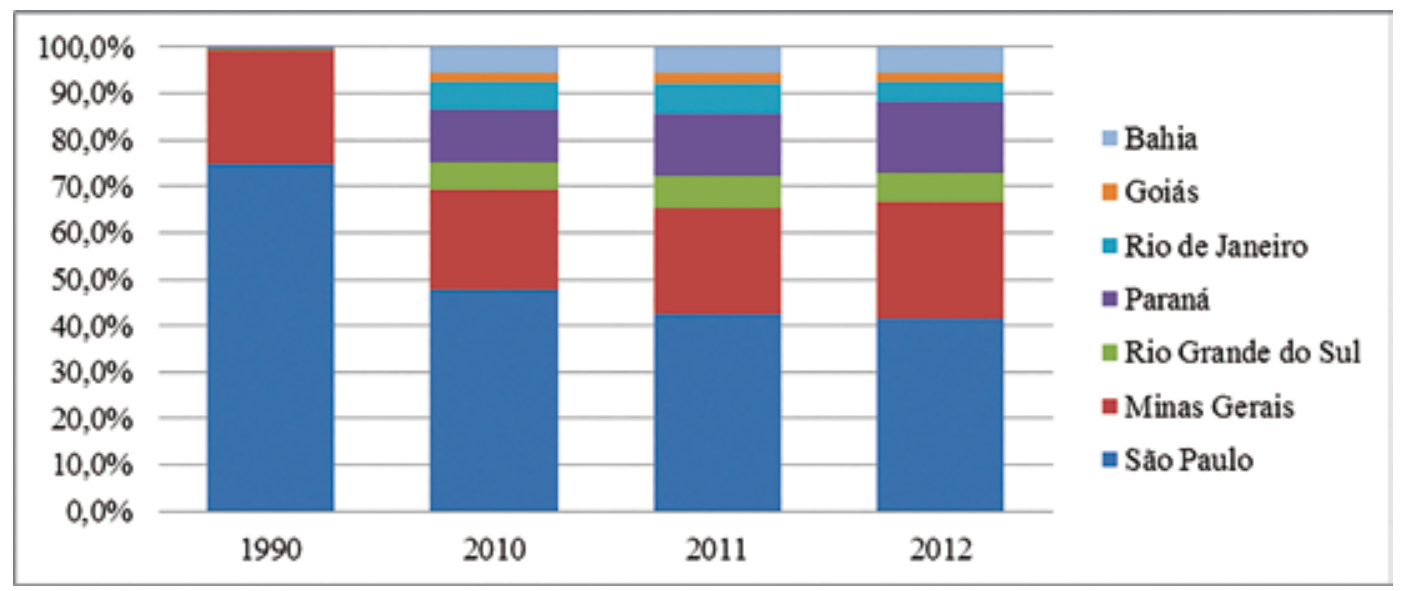

Fonte: elaboração dos autores com base em dados da Anfavea.

Em termos das marcas distribuídas no país, o Quadro 6 mostra que a maior concentração é em São Paulo, onde se encontram três das quatro maiores montadoras do país, além de outras quatro marcas importantes.

Quadro 6 - Empresas que produzem automóveis nos estados produtores do Brasil em 2013

\begin{tabular}{|l|l|}
\hline \multicolumn{1}{|c|}{ Estado } & \multicolumn{1}{c|}{ Empresa } \\
\hline São Paulo & Ford, General Motors, Honda, Hyundai, Mercedes-Benz, Toyota, Volkswagen \\
Minas Gerais & Fiat, Mercedes-Benz \\
Rio Grande do Sul & General Motors \\
Paraná & Nissan, Renault, Volkswagen, Volvo \\
Rio de Janeiro & Peugeot Citroën \\
Goiás & Mitsubishi \\
Bahia & Ford \\
\hline
\end{tabular}

Fonte: Anfavea (2013). 
Um dos efeitos de maior destaque da aplicação do regime especial foi a implantação da fábrica da Ford em Camaçari, na Bahia, em 2001, que se destaca na questão de uso de tecnologias inovadoras e produz modelos como o Fiesta $\mathrm{Ha}$ tch, o Fiesta Sedan e o EcoSport. Como o regime especial deveria terminar em 2010, naquele ano foram estendidos benefícios fiscais ao Nordeste, por meio da MP 512/2010. Como consequência, a Fiat, em dezembro de 2010, anunciou seu projeto para uma nova planta em Goiana, Pernambuco, com investimento inicial de 1 bilhão de reais. ${ }^{9}$

É interessante ressaltar que tais ações governamentais de âmbito nacional têm uma contrapartida estadual: a guerra fiscal. Nesse caso, são os próprios estados que oferecem incentivos de diversas ordens para atrair as empresas que planejam se instalar ou ampliar suas atividades no país. ${ }^{10}$ Como mostram Damasceno e Valente Júnior (2011), esse foi o caso da instalação de fábricas nos estados do Paraná e Rio Grande do Sul.

Com o desenvolvimento dessas novas regiões de produção, com consequentes melhorias em termos de infraestrutura, tecnologia e capacitação de mão de obra, e com a continuidade das políticas públicas que induzem o investimento nessas áreas, é provável que continue aumentando a importância dos novos estados produtores em relação aos tradicionais.

\section{Considerações finais}

O presente artigo identificou e mensurou diversas tendências, além de algumas alterações pontuais, que estão ocorrendo na estrutura da indústria automobilística brasileira. Algumas dessas tendências já haviam se iniciado na década de 1990, como verificou Pinho (1999), mas se aprofundaram desde então.

Embora permaneça em nível bastante elevado, a concentração do mercado brasileiro tem se reduzido continuamente, como decorrência do ingresso de novos fabricantes, seja via importação (em um primeiro momento) ou via produção em território nacional (mais recentemente). Em relação ao impacto da importação, a pesquisa mostra que o fluxo comercial passou por uma reversão nos últimos dez anos, à medida que o país passou de exportador líquido para importador líquido.

Essas mudanças decorreram tanto de políticas públicas específicas para o setor, como a redução das tarifas de importação na década de 1990, as políticas tributárias anticrise adotadas em 2008 e a maior disponibilidade de crédito para compra de veículos, quanto por questões conjunturais de mercado, tais como a apreciação 
cambial, o aumento da renda disponível dos consumidores brasileiros e a retração de outros mercados consumidores de veículos.

A política de oneração das importações de veículos, implementada em 2011, teve impacto de reduzir as importações desde então, mas a concentração do mercado deve continuar diminuindo à medida que essa política incentiva as firmas estrangeiras a se implantarem no Brasil.

Também como resultado do aumento de renda, da disponibilidade de crédito a juros mais reduzidos e prazos maiores e da importação de veículos que, embora tivessem melhor qualidade, tinham preços acessíveis, houve uma redução da participação de veículos de entrada e de mil cilindradas nas compras dos consumidores brasileiros. Em contrapartida, aumentaram as vendas de veículos de maior valor.

Por fim, o trabalho identificou a intensificação do deslocamento da produção dos estados tradicionais para outras regiões do país. Nesse caso, a tendência é decorrência direta de políticas públicas, tanto em nível federal (como o regime especial) quanto dos estados e municípios, que oferecem incentivos para atrair os novos investimentos.

Levando em conta o referencial teórico adotado por esta pesquisa, as mudanças estruturais constatadas apontam para uma melhoria no bem-estar social, uma vez que o poder das quatro grandes firmas que ainda dominam o mercado brasileiro tem sido restringido pelo ingresso de concorrentes.

Uma incerteza que persiste é se as políticas protecionistas adotadas em 2011 não estariam "blindando" as montadoras instaladas no Brasil da concorrência do produto importado, o que poderia reduzir a adoção de inovações tecnológicas e manter as firmas com lucros supranormais. Embora as novas políticas tenham mostrado a preocupação de atrelar os benefícios públicos a contrapartidas por parte da indústria, particularmente no tocante à geração de inovação, nível de investimento e de emprego, o sucesso desse novo enfoque ainda precisa ser analisado. 


\title{
Structural change at the Brazilian automobile market
}

\begin{abstract}
This paper analyzes the structural changes that have occurred in the Brazilian automobile market since the 1990's. There was identified a continuous decrease in market concentration, as consequence of the entrance of new firms. Despite of that, the Brazilian market still is highly concentrated. In terms of international trade, it was detected a new pattern as the country moved from net exporter to net importer of vehicles. The types of cars sold in Brazil have also modified, as the participation of popular low-cost vehicles is diminishing. This is a consequence of an increase in consumer income and a larger availability of credit. Another aspect identified in the study was a decrease in the share of the traditional states (São Paulo and Minas Gerais).
\end{abstract}

Keywords: Brazilian automobile market. Market concentration. Competition.

\section{El cambio estructural en el mercado brasileño de automóviles}

\section{Resumen}

En este trabajo se analizan los cambios estructurales que se han producido en el mercado automovilístico del Brasil desde la década de 1990. Se identificó una disminución continua de la concentración del mercado, como consecuencia de la entrada de nuevas empresas. A pesar de ello, el mercado brasileño aún está muy concentrado. En el comercio internacional, se detectó un nuevo patrón que el país pasó de exportador neto a importador neto de vehículos. Los tipos de automóviles vendidos en Brasil también han modificado, como la participación de vehículos de bajo costo es cada vez menor. Esto es una consecuencia de un aumento en los ingresos de los consumidores y una mayor disponibilidad de crédito. También se observó una disminución en la participación de los estados tradicionales (Sao Paulo y Minas Gerais) en el mercado nacional.

Palabras clave: Mercado automovilístico. Concentración del mercado. Competencia.

Classificação JEL: L1 - Market Structure, Firm Strategy, and Market Performance. 


\section{Notas}

1 Para análise sobre o regime automotivo, ver Negri (1999), Calandro (2000), Zauli (2000) e Hollanda Filho (2003), entre outros autores.

2 Alvarenga et al. (2010) estimam que, em 2009, 20,7\% das vendas seriam resultado da redução a zero desse imposto.

3 Para maiores detalhes sobre esses indicadores, ver Martin (1993).

4 Shepherd (1999) classifica os mercados em oligopólio fraco $(C R 4<40 \%$ e índice $H<0,1)$, oligopólio forte ( $C R 4>60 \%$ e índice $H>0,18$ ) e oligopólio moderado (intermediário). Levando essa classificação rigorosamente em conta, poder-se-ia dizer que o mercado brasileiro atende aos pré-requisitos de oligopólio forte até hoje. A partir de 2008, poderia ser considerado moderado, caso se observasse somente o índice $H$. De qualquer forma, a classificação de Shepherd é apenas sugestiva, e não definitiva.

5 Ver Business \& Economics Research Advisor (2014).

6 Informações do site da Fiat Brasil. Disponível em: <http://programapernambuco.fiat.com.br/\#home_scr>.

7 Para detalhes sobre a disputa interestadual, ver Santos e Burity (2001).

\section{Referências}

ALVARENGA, G. V. et al. Políticas anticíclicas na indústria automobilística: uma análise de cointegração dos impactos da redução do IPI sobre as vendas de veículos. IPEA, 2010. Texto para discussão 1512. Disponível em: <https://www.econstor.eu/dspace/bitstream/10419/91099/1/640454380. pdf>. Acesso em: 30 jun. 2013.

ASSOCIAÇÃO NACIONAL DOS FABRICANTES DE VEÍCULOS AUTOMOTORES. Anuário Estatístico. 2013. Disponível em: <http://www.anfavea.com.br>. Acesso em: 15 abr. 2013.

ASSOCIAÇÃO BRASILEIRA DE EMPRESAS IMPORTADORAS DE VEÍCULOS AUTOMOTORES - ABEIVA. Histórico de vendas no atacado. Disponível em: <http://>. Acesso em: 3 jun. 2012.

BARROS, D.; PEDRO, L. O papel do BNDES no desenvolvimento do setor automotivo brasileiro. 2010. Disponível em: <>. Acesso em: 17 maio 2013.

BRASIL. Casa Civil. Medidas Provisórias. 19 de dezembro de 1996. URL [On line]: http://www. planalto.gov.br/ccivil_03/mpv/quadro/_quadro\%20geral.htm. Acesso em 02 de setembro de 2013. BUSINESS \& ECONOMICS RESEARCH ADVISOR. Global automobile industry. 2014. Disponível em: <http://www.loc.gov/rr/business/BERA/issue2/industry.html>. Acesso em: 15 maio 2014.

CALANDRO, M. A indústria automobilística brasileira: integração produtiva no Mercosul, regimes automotivos e perspectivas. Revista Eletrônica FEE, Porto Alegre, v. 28, n. 1, p. 116-136, 2000. Disponível em: <revistas.fee.tche.br/index.php/ indicadores/article/viewFile/1661/2029>. Acesso em: 17 maio 2013.

COSTA, R. M.; HENKIN, H. Estratégias competitivas e desempenho da indústria automobilística no Brasil. In: ENCONTRO NACIONAL DE ECONOMIA, 40, 2012, Porto de Galinhas. Trabalhos completos... Porto de Galinhas, PE: Anpec, 2012. Disponível em: <http://www.anpec. org.br/novosite/br/encontro-2012\#AREA_8>. Acesso em: 2 nov. 2013.

DAMASCENO, W. S.; VALENTE JÚNIOR. A. S. O setor automotivo e oportunidades para o Nordeste. Fortaleza: Banco do Nordeste; Etene, 2011. Disponível em: <http://econometrix.com.br/pdf/ Conjuntura_Economica_BNB_ano_6_n_27.pdf>. Acesso em: 15 ago. 2013. 
FEDERAÇÃO NACIONAL DA DISTRIBUIÇÃO DE VEÍCULOS AUTOMOTORES - FENABRAVE. Informativo FENABRAVE. Diversos. Disponível em: <http://www.tela.com.br/dados_ mercado/emplacamentos/index.asp?coditem=1>. Acesso em: 13 nov. 2013.

HOLLANDA FILHO, S. B. Nota: o estabelecimento de um regime automotivo diante da cração da OMC. Estudos Econômicos, São Paulo, v. 33, n. 4, p. 771-792, 2003.

MARTIN, S. Industrial economics: economic analysis and public policy. 2. ed. Englewood Cliffs: Prentice Hall, 1993.

MASON, E. S. Price and production policies of large-scale enterprise. American Economic Review, Pittsburgh, PA, v. 29, p. 61-74, 1939.

NEGRI, J. O custo de bem-estar do regime automotivo brasileiro. Pesquisa e Planejamento Econômico, Rio de Janeiro, v. 29, n. 2, p. 215-242, 1999.

PINHO, M. Mudança estrutural na indústria automobilística brasileira: a entrada de novos concorrentes. In: ENCONTRO NACIONAL DE ENGENHARIA DE PRODUÇÃO, 19, 1999, Rio de Janeiro. Anais eletrônicos... Rio de Janeiro: Abepro, 1999. Disponível em: <http://www.abepro. org.br/biblioteca/enegep1999_a0190.pdf>. Acesso em: 2 nov. 2013.

SANTOS, A. M. M. M.; BURITY, P. O complexo automotivo. Biblioteca Digital BNDES, 2002. Disponível em: <http:/www.bndes.gov.br/SiteBNDES/export/sites/default/ bndes_pt/Galerias/ Arquivos/conhecimento/livro_setorial/setorial06.pdf>. Acesso em: 25 set. 2013.

SHEPHERD, W. G. The Economics of Industrial Organization. 4th. Ed., Prospect Heights: Waveland Press, Inc. 1999.

ZAULI, E. M. Políticas públicas e targeting setorial - efeitos da nova política industrial sobre o setor automobilístico. Revista de Economia Política, São Paulo, v. 20, n. 3, p. 76-94, 2000. 